\title{
BLOQUE CELULAR EN LESIONES QUÍSTICAS Y SÓLIDAS DE GLÁNDULA MAMARIA
}

Alexandra Espitia Ríos, Andrea Garzón Rozo*

\section{Resumen}

El objetivo de esta investigación fue estandarizar la utilización del bloque celular en el diagnóstico de las lesiones sólidas y quisticas de la glándula mamaria. Incluye desde la toma de la biopsia para determinar si hay material suficiente, tiempo de centrifugación, número de láminas citológicas, conservación de la morfología y la recuperación de material para procesamiento en parafina con el fin de realizar cortes histológicos rutinarios, receptores hormonales y coloraciones especiales.

\section{Introducción}

La biopsia por aspiración con aguja fina es un método adecuado, seguro y fiable para estudiar lesiones quísticas y sólidas de la glándula mamaria. El bloque celular es un procedimiento de diagnóstico histológico que se realiza con material obtenido mediante biopsia por aspiración con aguja fina (Bacaf). Esta técnica conserva el material intacto ya que se obtienen bloques en parafina de fácil manejo, pues los tejidos adquieren tal consistencia que permite realizar cortes muy delgados con mínima modificación de la morfología celular.

Con el bloque celular se evalúa la eficacia del proceso histológico (en la extracción del material, centrifugación, fijación, deshidratación, aclaramiento, impregnación e inclusión directa en parafina). Para la estandarización de la técnica de bloque celular fueron analizadas las siguientes variables:

1. Cantidad de material enviado en la Bacaf.

2. Manipulación por parte del técnico encargado.

3. Tiempo de centrifugación y revoluciones por minuto.

4. Extracción del material del tubo de ensayo.

5. Bacaf no apropiado para la técnica histológica.

\footnotetext{
Estudiantes $5^{\circ}$. Semestre Facultad de Citohistotecnología, Fundación Universitaria de Ciencias de la Salud.

** Este trabajo fue realizado bajo la tutoría del Dr. Juan Carlos Bonilla, médico patólogo del Hospital de San José. Instructor Asociado de la Fundación Universitaria de Ciencias de la Salud y del Dr. Jaime Alberto Ortega, médico radiólogo de la Clínica San Pedro Claver
}

La finalidad del proceso es obtener un bloque fácil de manejar, de dureza homogénea, plasticidad y elasticidad adecuadas, que permitan realizar cortes de buena calidad sin distorsión ni fragmentación de las estructuras del tejido.

\section{Materiales y métodos}

La recolección de muestras se llevó a cabo entre mayo de 2002 y mayo de 2003 en Bogotá.DC. Se recogieron 204 de 103 pacientes remitidas a citopunción guiada por ecografia en la Clínica San Pedro Claver. Cada muestra fue fijada en isopropanol al $96 \%$ y luego se envió en tubo de ensayo al departamento de histopatología para comenzar el proceso y elaboración del bloque celular.

Se procesaron de la siguiente forma: toma de la muestra, fijación, radicación del material, centrifugación, deshidratación, aclaramiento, impregnación, inclusión, corte, pesca, coloración, montaje y lectura microscópica. Se ajustó el tiempo de centrifugación a la cantidad de líquido recibido en el laboratorio, como aparece en la (Tabla 1).

Después del proceso histológico las muestras fueron examinadas por el patólogo, quien valoró la calidad de conservación de la morfología celular (relación núcleocitoplasma), los artificios de coloración y montaje en las láminas procesadas por bloque celular y la celularidad de éste. 
Para establecer la calidad morfológica de las células, tanto benignas como malignas, se observa la tinción del núcleo y citoplasma (Figuras 1, 2,3).

Para determinar la celularidad se compararon las láminas procesadas por citología y por bloque celular. Por último, para determinar los artificios como son los que surgen en la coloración y el montaje, se tomaron las muestras procesadas por bloque celular al terminar el paso por hematoxilina- eosina, clasificándose como coloración eosinófila o basófila. Los artificios de montaje, se observaron en la lectura microscópica como grumos de resina.

\section{Hallazgos}

En cuanto a la estandarización del tiempo en la centrífuga, se colocó una gota del sobrenadante en una lámina para observar al microscopio. Cuando hubo presencia de células se colocó más tiempo en la centrífuga; si era acelular, el tiempo era correcto. Al realizarlo de

Tabla 1. Tiempos estándar para centrifugación

\begin{tabular}{cl} 
CANTIDAD (c.c.) & TIEMPO (minutos) \\
\hline 0,4 a 0,5 c.c. & 5 minutos \\
0,6 a 0,9 c.c. & 7 minutos \\
1,0 a 4,0 c.c. & 8 minutos \\
5,0 a 10 c.c & 10 minutos \\
más & 12 a 15 minutos
\end{tabular}

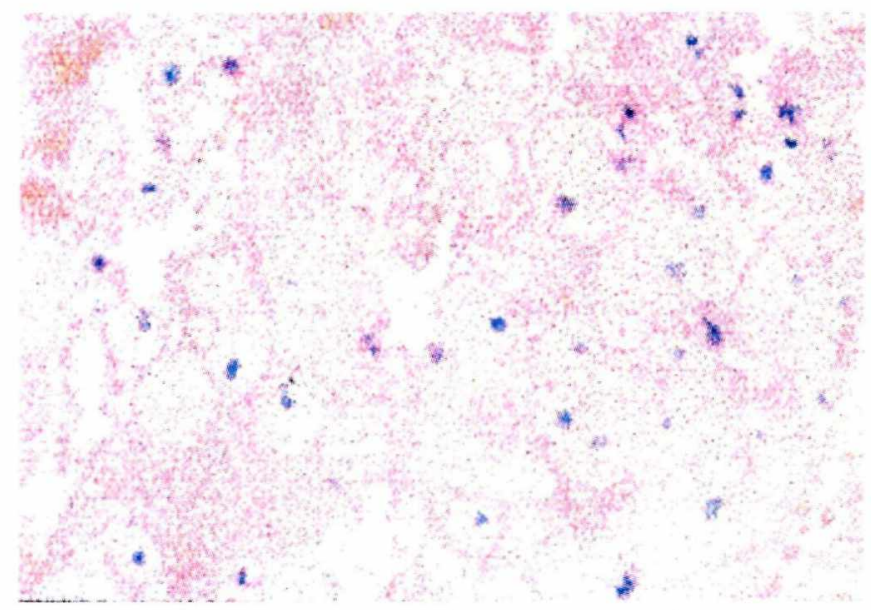

Figura I. Imagen del corte del bloque celular donde se observan histiocitos espumosos con un fondo hemorrágico proteináceo. esta manera, las células no mostraron alteraciones morfológicas.

Las 204 muestras se centrifugaron primero durante tres minutos a 1.500 r.p.m. El 100\% mostró celularidad en el sobrenadante, por lo cual agregaron tiempos adicionales hasta que el sobrenadante fuera acelular, así: un segundo tiempo de 5 minutos para 117 muestras, un tercer tiempo de 7 minutos a 50, un cuarto de 9 minutos aplicado a 27 muestras, y el quinto de 10 minutos para 10 muestras (Gráfica 1).

En cuanto a la coloración, de 204 muestras se utilizó hematoxilina - eosina, obteniendo $169(83 \%)$ con coloración normal, $20(10 \%)$ con coloración eosinófila intensa y pequeños acúmulos de ésta y 15 (7\%) con coloración basófila intensa (Gráfica 2).

El montaje con resina causó otro artificio que dificultó la adecuada lectura microscópica así: 194 muestras

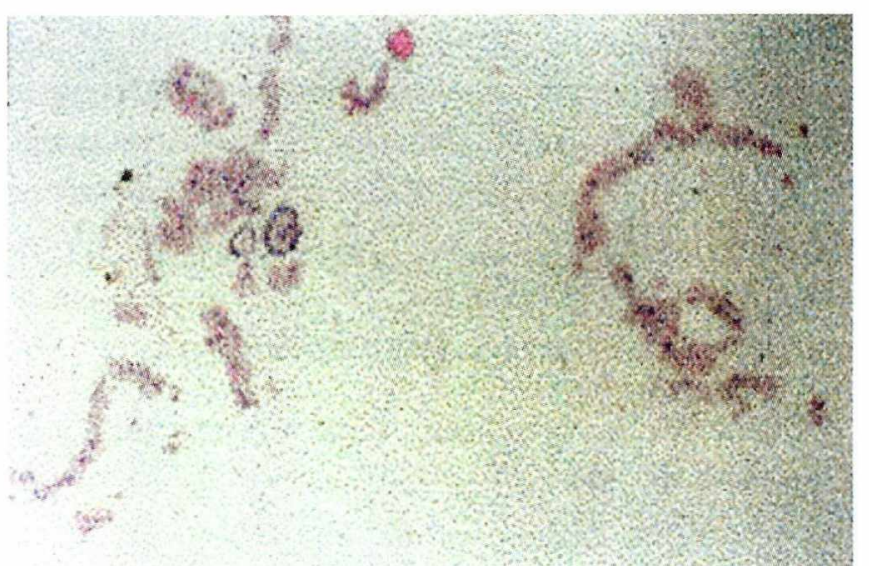

Figura 2. Se observa metaplasia aprocrina y ductos.

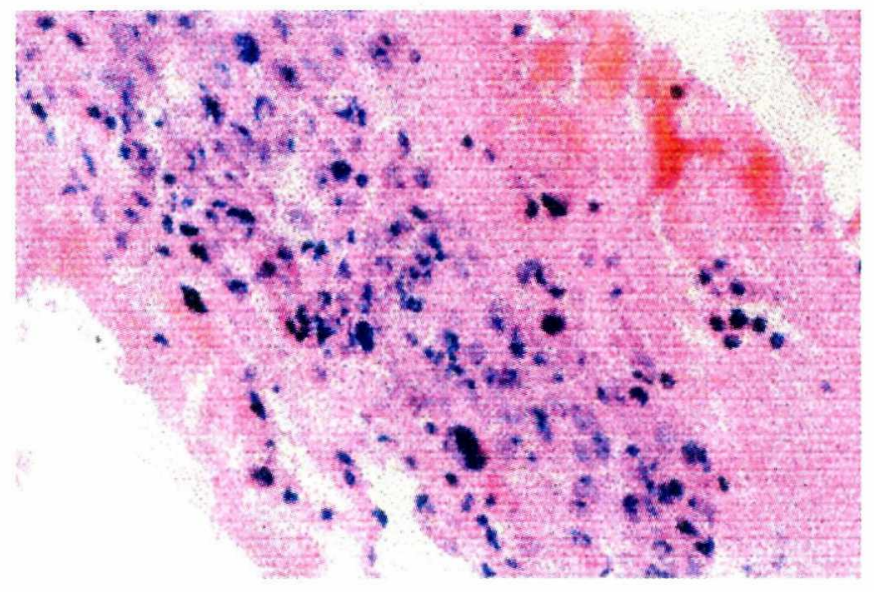

Figura 3. Se ven células tumorales en cariorrexis. 
(95\%) con uniformidad, montaje homogéneo, nitidez en la imagen y $10(5 \%)$, con resina en grumos que da una imagen inadecuada (Gráfica 3).

En cuanto a la celularidad, el bloque fue acelular en 76 muestras (37\%) y $124(63 \%)$ con material celular apto para diagnóstico (Gráfica 4).
En los extendidos citológicos, en 95 muestras (47\%) el material fue acelular, insuficiente para diagnóstico, y 109 (53\%) celular apto para diagnóstico (Gráfica 5).

De las 204 muestras procesadas por bloque celular, 10 fueron acelulares distribuidas así: 7 inadecuadas por tiempo de centrifugación y elaboración y 3 presentaron material hemorrágico.

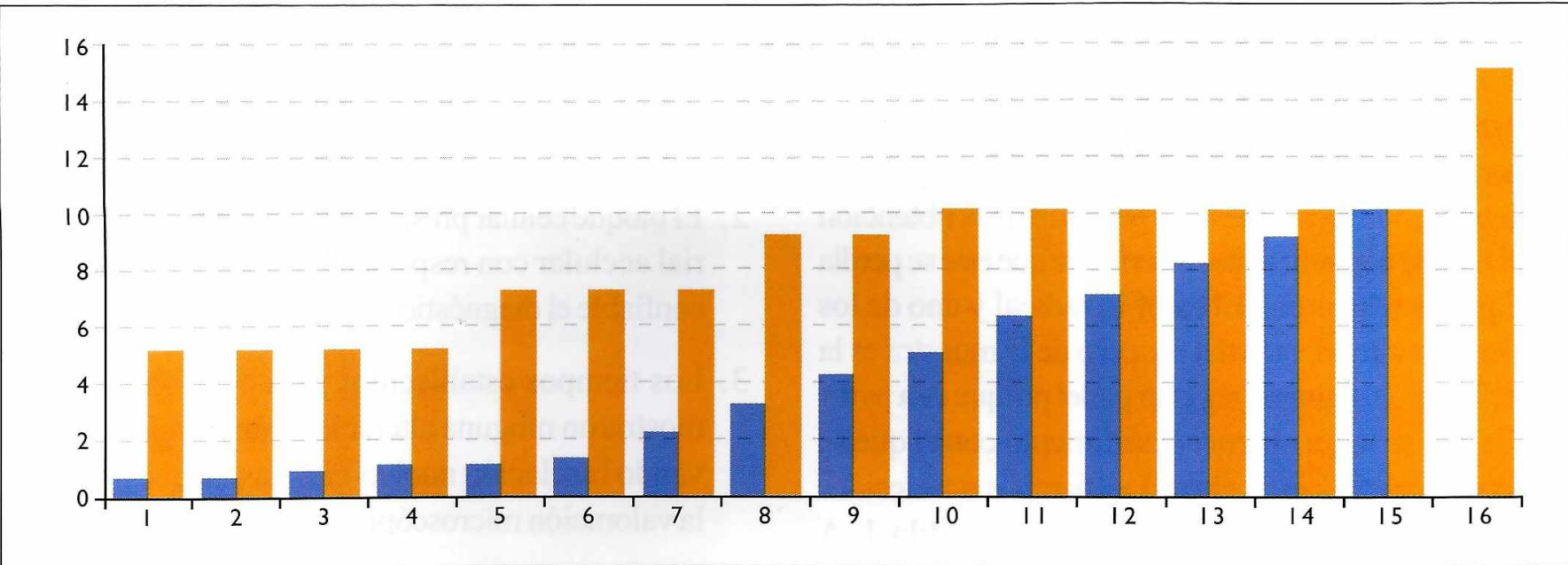

Gráfica I. Tendencia lineal: volumen vs. tiempo.

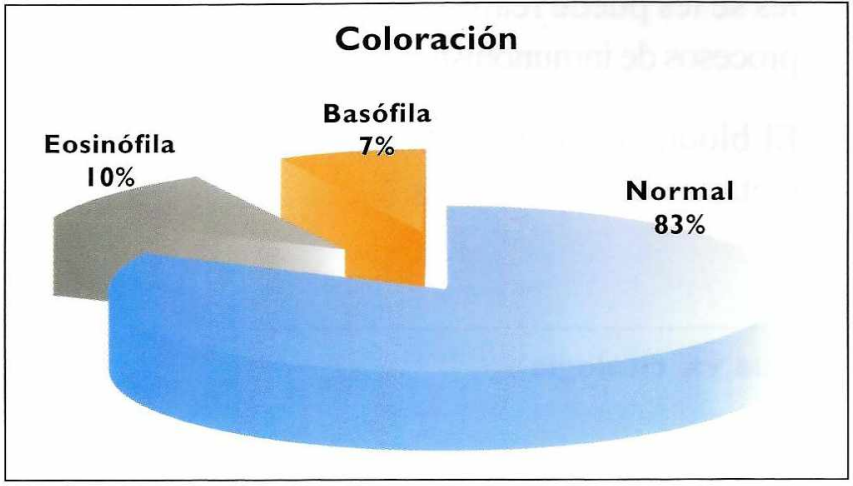

Gráfico 2. Porcentaje de artificios en la coloración

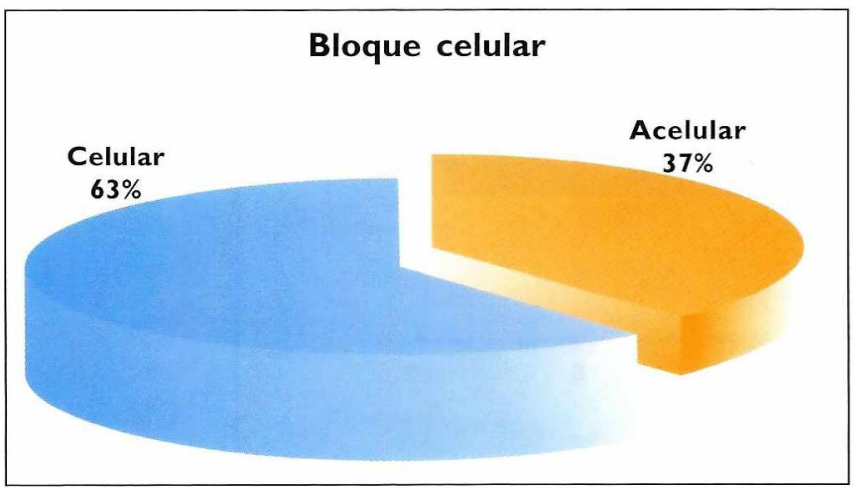

Gráfica 4. Proporción de celularidad obtenida por bloque celular

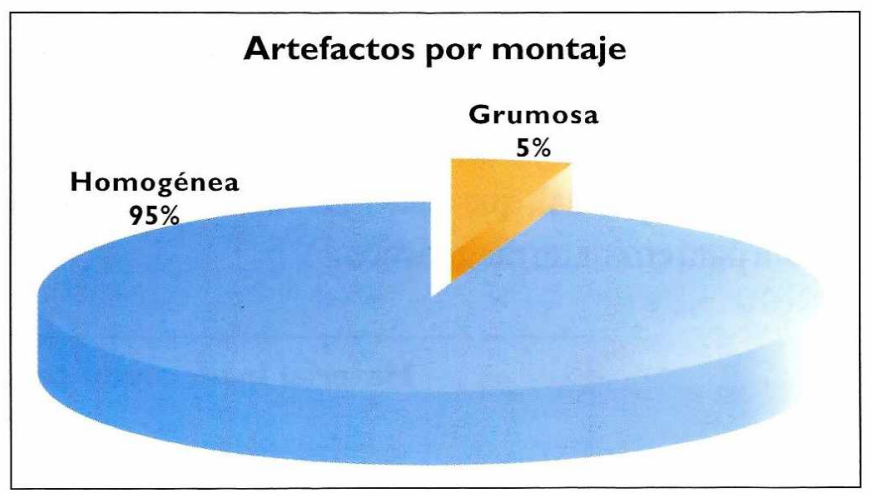

Gráfica 3. Porcentaje de artificios en el montaje con resina.

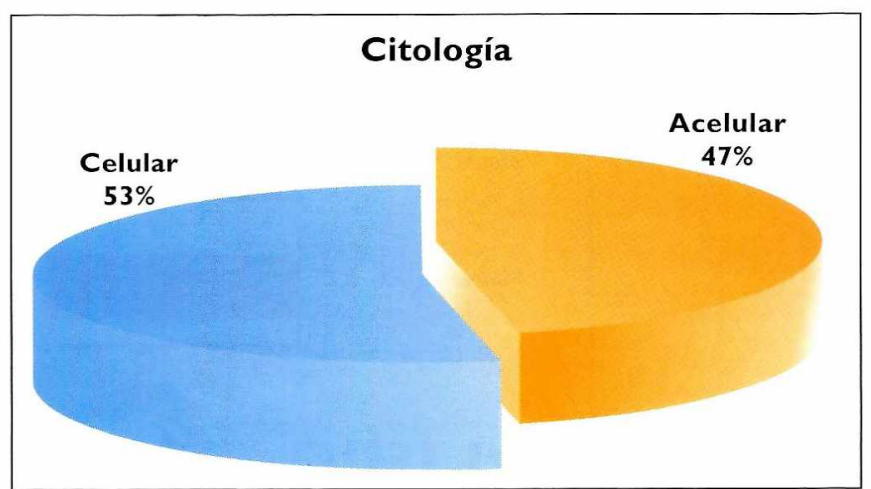

Gráfica 5. Proporción de celularidad por citología. 
En citología 13 fueron acelulares distribuidas así: 3 inadecuadas y 10 hemorrágicas (Gráfica 6).

\section{Discusión}

El propósito del estudio fue demostrar que el bloque celular puede ser estandarizado y empleado en tomas de líquidos por Bacaf y que ofrece al patólogo material adecuado, bien preservado y con sobrante celular para realizar estudios posteriores, como son las coloraciones especiales y los receptores hormonales.

Para el procesamiento de las muestras fue necesario revisar la metodología empleada en el laboratorio y pensar en algunas modificaciones que permitieran la obtención de un bloque con suficiente material, ya que este se perdía en el proceso habitual. El cambio radical y uno de los más importantes dentro del proceso de la muestra es la centrifugación. Cumple un gran papel porque es a partir de ella que se logra obtener el sedimento con el que se confeccionará el bloque celular. Los tiempos establecidos en este estudio se pueden observar en la tabla 1. A partir de este punto y solo hasta la lectura microscópica se pudo valorar la calidad de la muestra en cuanto a fondo, proporción y morfología celular, dejando al bloque en ventaja por disminución de material acelular, adecuada relación núcleo citoplasma e imagen histológica con fondos parejos y homogéneos, sin superposición del material epitelial, que hace más sencilla y rápida la lectura para emitir un diagnóstico.
En el estudio se demuestra como el bloque puede servir de apoyo en el momento de emitir un diagnóstico, sin necesidad de reemplazar la citología convencional.

\section{Conclusiones}

A partir de los resultados del trabajo, se pueden concluir los siguientes aspectos:

1. Se pudo comprobar que para la estandarizacion del bloque celular es necesario tener material adecuado, cantidad suficiente de muestras procedente de la Bacaf y un buen manejo por parte del histotecnólogo.

2. El bloque celular presenta una disminución de material acelular con respecto a la citología y hace más confiable el diagnóstico.

3. Los tiempos establecidos para centrifugación no mostraron ninguna alteración morfológica, conservando la relación núcleo-citoplasma que hace apta la valoración microscópica.

4. El bloque celular permite la existencia de material celular para cortes y estudios posteriores, a los cuales se les puede realizar coloraciones especiales y procesos de inmunohistoquimica.

5. El bloque celular es confirmatorio para lesiones metastásicas y profundas.

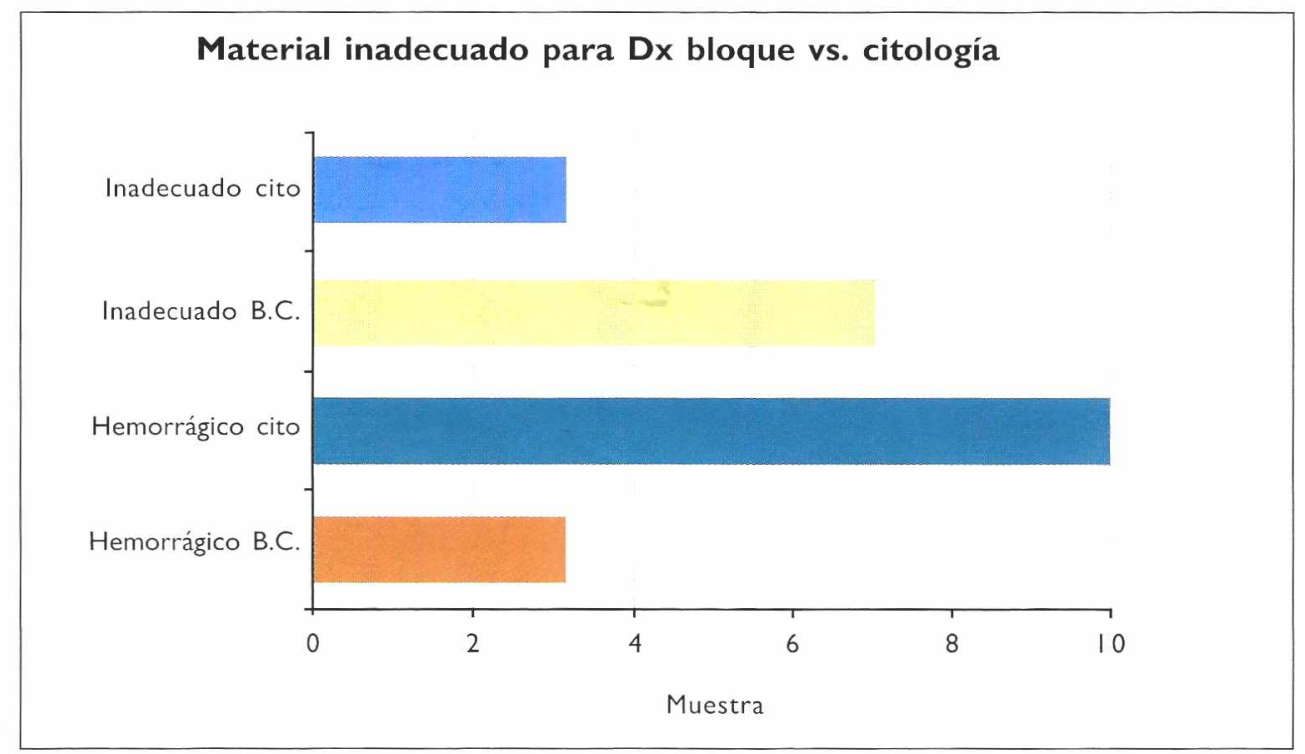

Gráfica 6. Comparación del bloque celular y la citología en cuanto a material inadecuado para diagnóstico. 
6. La técnica establecida permite al patólogo una imagen histológica que hace más fácil la interpretación microscópica y reduce el tiempo de lectura con respecto a la citología.

\section{Lecturas recomendadas}

- Fernandez-Cid Fellonera A, López Marin L. Citopatología Ginecología y Mamaria.2 ed. Bogotá: Salvat, p. 27.
- García del Moral R. Laboratorio de anatomía patológica. Madrid: Mac Graw-Hill lnteramericana, 1995; p.75-76.

- Montera Ruiz, J. Historia de la patologia mamaria. Control de calidad en patologia mamaria. Disponible en http: // www.united.Edu.

- Robbins S. Patología estructural y funcional. 6 ed. Interamericana, 2000. p. 2-9.

- Zornoza Celaya G. Senología práctica. Madrid: Interamericana Mc Graw -Hill. p.75-76.

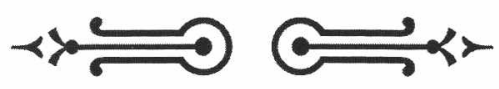

